[DOI: 10.24214/jecet.A.10.4.45159.]

Jaurnal of Environmental Science, Computer Science and Engineering \& Technology

An International Peer Review E-3 Journal of Sciences and Technology

Available online at www.jecet.org

Section A: Environmental Science

Research Article

\title{
Motor vehicle emission measurement model based on dynamic traffic information
}

\author{
Chunyan ZHENG' ${ }^{1}$, Guanglei $\mathrm{OU}^{2}$, Yujiao $\mathrm{HAO}^{3}$, Jiaojiao $\mathrm{LI}^{3}$, \\ Congcong $\mathrm{CAO}^{2}$ and Dong $\mathrm{GUO}^{3}$

\begin{abstract}
${ }^{1}$ Shandong University of Technology, School of Management, Zibo City, China
${ }^{2}$ Zibo Environmental Pollution Prevention and Control Centre, Zibo City, China
\end{abstract} \\ ${ }^{3}$ Shandong University of Technology, School of Traffic and Vehicle Engineering, Zibo \\ City, China
}

Received: 16 August 2021; Revised: 30 August 2021; Accepted: 05 September 2021

\begin{abstract}
In order to accurately evaluate the emission situation of urban road network, this paper takes Zibo city as the research object, obtains the second-by-second emission data reflecting the actual road characteristics and vehicle characteristics through vehicle emission experiments, and establishes a motor vehicle emission measurement model coupled with the real-time road conditions using the vehicle experimental data. It is verified that the error of pollutant emissions calculated by the model is less than $10 \%$ of the actual measured value, and the accuracy of the model is good, which can be applied to the measurement of motor vehicle emissions in Zibo city road network and provide data support for the subsequent formulation of emission reduction measures.
\end{abstract}

Keywords: urban road network; in-vehicle experiment; dynamic traffic information; emission model 


\section{INTRODUCTION}

With the continuous development of China's national economy and automobile industry, the number of car ownership has proliferated, and in 2019, the number of motor vehicles in the country reached 348 million ${ }^{[1]}$, which has brought a series of problems such as national energy shortage and aggravated environmental pollution. According to the classification statistics of urban air pollutant sources, emission gases such as $\mathrm{CO}, \mathrm{HC}$, and NOx from vehicle exhaust have become the number one air pollution source in cities. in 2019, the total amount of motor vehicle pollutant emissions in the country was 16.038 million tons ${ }^{[1]}$. $\mathrm{CO}, \mathrm{HC}$, and NOx in exhaust gases cause direct or potential harm to urban environment and human health ${ }^{[2]}$. Therefore, the urgency of motor vehicle pollution prevention and control due to the proliferation of motor vehicle ownership has become increasingly evident. How to establish a motor vehicle emission measurement model coupled with dynamic traffic network and accurately calculate the actual urban motor vehicle emissions is the primary link to carry out motor vehicle prevention and control.

Foreign research on motor vehicle emissions is relatively early, and the United States, Europe and other countries have established a series of emission measurement models at different scales according to the local actual situation since the 1970s; foreign emission models that have been widely used in recent years are divided into macro, meso and micro according to the research purposes and application levels ${ }^{[3]}$, and the models mainly include MOBILE model ${ }^{[4]}$, COPERT model ${ }^{[5]}$, IVE model ${ }^{[6]}$, MOVES model ${ }^{[7]}$, CMEM model and EMIT model, etc.

Considering the problem of great regional differences in motor vehicle emissions due to the complex and diverse topography and climate conditions in China, the Ministry of Ecology and Environment of China developed the China Vehicle Emission Model (CVEM) ${ }^{[8]}$ in 2006 by conducting a large number of actual emission experiments in typical cities with different climatic conditions and topographic features. which provides a basis and reference for the establishment of motor vehicle emission models at the provincial, autonomous region or city scale.

Through reading the related literature at home and abroad, it is found that most scholars at home and abroad use the existing emission models to complete the approximate accounting of urban motor vehicle pollutant emissions, but it is difficult to fully and accurately reflect the complex situation of actual road emissions, resulting in inaccurate evaluation results.

To address the shortcomings of existing studies, this paper uses on-board emission experiments to obtain second-by-second emission data reflecting the actual road characteristics and vehicle characteristics, and uses the on-board experimental data to establish an emission model coupled with real-time road conditions to accurately evaluate the emission situation of urban road networks.

\section{ACTUAL ROAD EMISSION TEST EXPERIMENT}

\subsection{Experimental platform construction:}

Based on MAHA METDH6.3 portable measuring instrument to build an on-board measuring system, the structure schematic diagram is shown in Figure 1. The complete on-board real-time testing system consists of exhaust gas collection and processing module, emission testing and analysis module, and motor vehicle driving condition monitoring module. Firstly, the test system can realize the experiment of pollutant emission during the actual driving of motor vehicle, study the influence of engine load, road environment, etc. on emission, and the relationship between motor vehicle speed, acceleration and emission; secondly, through the OBD interface software can automatically read the car OBD status and obtain various vehicle parameters; meanwhile, through the GPS module to monitor and record the 
driving trajectory of motor vehicle, through The above data can calculate the emission factors of each pollutant, and provide data support for establishing motor vehicle emission model.

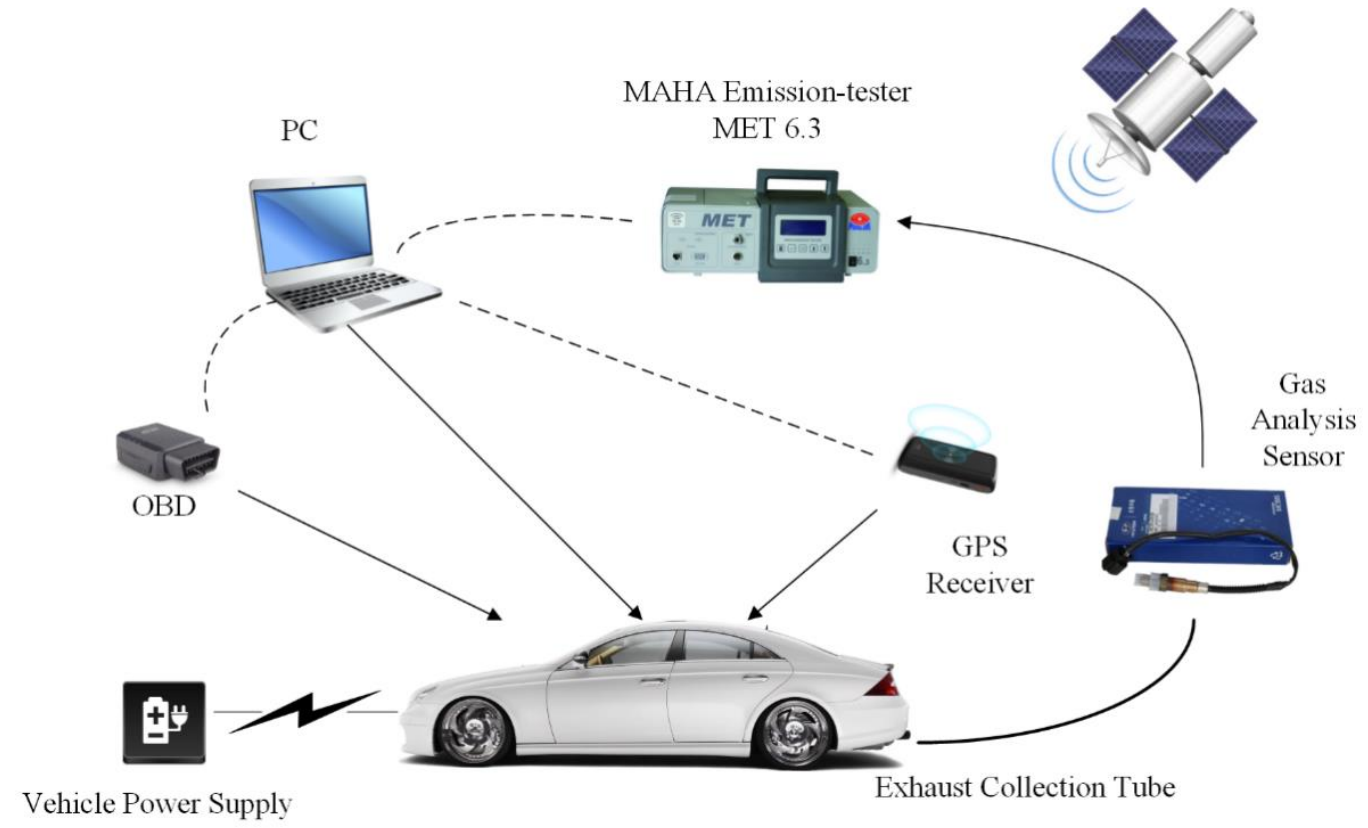

Figure 1: MAHA METDH6.3 portable measurement system installation diagram

\subsection{On-board emission experiments}

2.2.1 Experimental design: The purpose of this paper is to obtain a realistic reflection of the emission pollution status of motor vehicles in urban traffic flow through actual road vehicle experiments. The experimental protocol is designed as follows.

(1) To ensure the accuracy and representativeness of the experimental results, representative models of gasoline passenger cars on urban roads were selected as the experimental vehicles (displacement of $1.3 \mathrm{~L}-1.8 \mathrm{~L}$ ), and the emission levels of the experimental vehicles were tested to meet the relevant national standards, and the specific vehicle technical data of the 16 selected gasoline passenger cars are shown in Table 1.

Table 1: Technical parameters of the experimental vehicle

\begin{tabular}{lllll}
\hline Vehicle Type & Year & $\begin{array}{l}\text { Miles } \\
\text { traveled/km }\end{array}$ & $\begin{array}{l}\text { Emission } \\
\text { standards }\end{array}$ & Displacement/L \\
\hline Buick Sprinter & 2011 & 52569 & Country 4 & 1.8 \\
Volkswagen Maitreya & 2011 & 121461 & Country 4 & 1.8 \\
Dongfeng Scenery & 2013 & 50,000 & Country 4 & 1.3 \\
Mitsubishi Impreza & 2013 & 63190 & Country 4 & 1.8 \\
Crowd Sprint & 2014 & 36469 & Country 4 & 1.4 \\
Ford Focus & 2014 & 42060 & Country 4 & 1.6 \\
Volkswagen New Santana & 2014 & 40000 & Country 4 & 1.6 \\
Volkswagen Passat & 2014 & 280000 & Country 4 & 1.8 \\
\hline
\end{tabular}




\begin{tabular}{lllll}
\hline Great Wall Haval H6 & 2015 & 33139 & Country 5 & 1.5 \\
New Volkswagen Jetta & 2015 & 82000 & Country 5 & 1.6 \\
Buick Infinity & 2016 & 30413 & Country 5 & 1.5 \\
Toyota Corolla & 2016 & 28153 & Country 5 & 1.6 \\
Corvette & 2016 & 21356 & Country 5 & 1.5 \\
Volkswagen Ranger & 2017 & 13455 & Country 5 & 1.6 \\
Volkswagen Sprint & 2017 & 14234 & Country 5 & 1.6 \\
Baojun 510 & 2017 & 11236 & Country 5 & 1.5 \\
\hline
\end{tabular}

(2) Because of the different levels of roads in the urban road system because of their set role, traffic functions and other different, the impact on vehicle driving is also different. Therefore, the experimental route was selected from a large number of major traffic roads in five districts and three counties of Zibo city, including four grades of roads, including expressways, trunk roads, secondary roads and feeder roads, in order to analyze the impact of different road grades on vehicle emissions.

(3) The test time was chosen as the peak commuting period, the flat daytime period and the low night time period to obtain the vehicle operation data, fuel consumption and emission information under different traffic flow conditions, as shown in Table 2.

Table 2: Actual road emission experiment time

\begin{tabular}{ccc}
\hline $\begin{array}{c}\text { Peak } \\
\text { commuting hours }\end{array}$ & $\begin{array}{c}\text { Daytime peak } \\
\text { period }\end{array}$ & $\begin{array}{c}\text { Nighttime Low } \\
\text { Period }\end{array}$ \\
\hline $6.30-7.30$. & $9.30-11.00 ;$ & $19.30-21.00$ \\
$16.30-18.00$ & $14.50-15.50$ & \\
\hline
\end{tabular}

(4) Driving behavior is one of the important factors affecting vehicle fuel consumption and emission variability, but since this paper aims to study the emission pattern of motor vehicles in traffic flow, the influence of driving behavior is not considered, and drivers are only required to follow the normal driving behavior in traffic flow.

\subsubsection{Experimental data acquisition and processing}

(1) Data collection. Experimental data collection process is the key link of the whole experiment. During the experiment, the PC terminal will automatically save the second-by-second emission data and save them in the database, and save the data of one experiment as an index with time as the number, which is convenient for the experimenter to search, export (export to Excel file), delete and map view.

(2) Data processing. Since the data table generated by MAHA METDH6.3 has been pre-processed accordingly, the experimental data can be directly quoted for the derivation of fuel consumption and emission models under the normal condition of the experimental process. However, due to the long experimental time and many experimental data, there will inevitably be errors in the experimental process, so the experimenter needs to take appropriate processing measures for the experimental 
problems to ensure the accuracy of the experimental data calculation and analysis as well as the measurement model. The specific operation is as follows.

(a).Data loss handling. There are two main reasons for data loss caused during the experiment. Instrument connection is unstable or disconnected, resulting in missing experimental data; due to the experimental vehicle's own problems cannot form the data of some specific variables. The most frequent problem in the experimental process is missing GPS data. Therefore, during the analysis of experimental results, incomplete data need to be organized and deleted.

(b).Vehicle emission data does not match with engine data. Mainly manifested as a delay in the gas analyzer collection and analysis gas time, resulting in the data being out of sync at that moment, mainly due to the gas flow time in the exhaust gas collection tube and the airflow being blocked, etc. Therefore, the experimenter needs to be aligned for the problem. Of course, due to the precision of the experimental instrumentation and the sampling frequency, minor delays have less impact on the analysis of the entire data, so such errors are usually not considered.

\section{EMISSION MODELING}

The emission measurement of motor vehicles in the actual road driving consists of fuel consumption and emission of the road section of the path driven and the intersection. In this paper, we analyze the VSP distribution law between different speed zones of four classes of roads by considering urban roads and vehicle driving states. Since the experimental vehicles contain two standards, National IV and National V, the data are counted separately according to the emission standards, and finally reintegrated according to the ratio of vehicle ownership of the two standards to obtain the motor vehicle emission factors in different average speed zones of the four grades of roads, and finally establish the motor vehicle roadway emission measurement model applicable to dynamic traffic information. The specific design idea is shown in Figure 2.

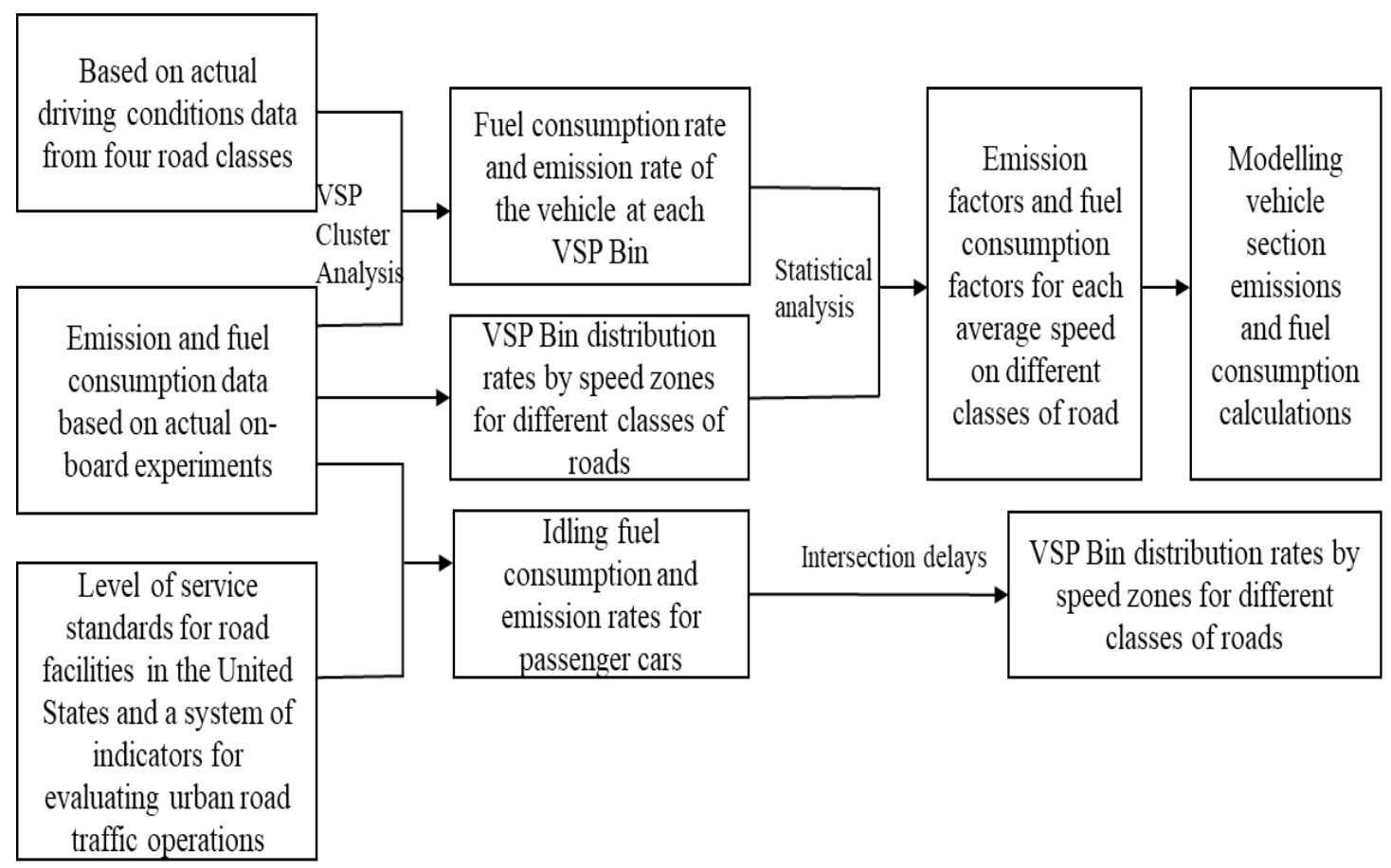

Figure 2: Model design ideas 
3.1 Road segment emission measurement model: The speed emission correction factor is an important parameter to assess the effect of speed change on vehicle emission. Based on the obtained measured working condition data and emission rate data, the factor of $30-40 \mathrm{~km} / \mathrm{h}$ interval on the main road is selected as the benchmark, and the correction factors of other grade roads and speed intervals are obtained, which are calculated as Equation 1, and the specific results are shown in Table 3.

$$
V C F=\frac{P E F_{\mathrm{v}, \mathrm{r}}}{P E F_{\text {base }}}
$$

where $V C F$ denotes the correction factor with average speed as v; $P E F_{v, r}$ denotes the fuel consumption factor and emission factor, and $P E F_{\text {base }}$ denotes the baseline fuel consumption factor and emission factor.

Table 3 Average speed correction factor for gasoline vehicles

\begin{tabular}{|c|c|c|c|c|c|c|}
\hline \multirow{2}{*}{ Contaminants } & \multirow{2}{*}{ Road Type } & \multicolumn{5}{|c|}{ Speed interval $(\mathrm{km} / \mathrm{h})$} \\
\hline & & $<20$ & $20-30$ & $30-40$ & $40-60$ & $>60$ \\
\hline \multirow{4}{*}{$\mathrm{CO}$} & Expressway & 1.77 & 1.41 & 0.99 & 0.96 & 0.95 \\
\hline & Main roads & 1.35 & 1.18 & 1.00 & 0.98 & - \\
\hline & $\begin{array}{l}\text { Secondary } \\
\text { roads }\end{array}$ & 1.54 & 1.24 & 1.01 & 0.97 & - \\
\hline & Branch Road & 1.66 & 1.21 & 1.04 & 0.96 & - \\
\hline \multirow{4}{*}{$\mathrm{HC}$} & Expressway & 1.69 & 1.33 & 0.98 & 0.95 & 0.90 \\
\hline & Main roads & 1.27 & 1.1 & 1.00 & 0.99 & - \\
\hline & $\begin{array}{l}\text { Secondary } \\
\text { roads }\end{array}$ & 1.46 & 1.16 & 1.01 & 0.98 & - \\
\hline & Branch Road & 1.53 & 1.18 & 1.03 & 0.97 & - \\
\hline \multirow{4}{*}{ NOx } & Expressway & 1.42 & 1.09 & 1.05 & 1.03 & 0.98 \\
\hline & Main roads & 1.38 & 1.15 & 1.00 & 0.98 & - \\
\hline & $\begin{array}{l}\text { Secondary } \\
\text { roads }\end{array}$ & 1.35 & 1.12 & 0.99 & 0.99 & - \\
\hline & Branch Road & 1.34 & 1.08 & 0.96 & 0.96 & - \\
\hline
\end{tabular}

The study is based on the on-board test data of each experimental road section, and the emission factor and fuel consumption are obtained by substituting the road grade and average speed, and the fuel consumption and emission simulation of each road section of the experimental route is completed by combining the road length and other information, as shown in Equation 2.

$$
E_{\mathrm{r}}=\sum_{i=1}^{n} K \cdot E F_{i} \cdot L_{i}
$$


Where, $E_{r}$ denotes the total emissions of a certain gas or total fuel consumption in $\mathrm{g}$ for the possible passing $\mathrm{n}$ road sections, respectively; $K$ denotes this speed emission or fuel consumption correction factor; $E F_{i}$ denotes the emission factor or fuel consumption corresponding to the current average speed of the $\mathrm{i}^{\text {th }}$ road section; Li denotes the road section length of the passing $\mathrm{i}^{\text {th }}$ road section in $\mathrm{km}$.

3.2 Cross-port emission measurement model: As the connection point of urban roads and the collection and distribution point of traffic flow, intersections have more complicated traffic characteristics compared with road sections. Therefore, the article only considers the emissions under the "idling waiting light" condition ${ }^{[9-11]}$. In this paper, we refer to the American authoritative road capacity classification standard HCM2000 road service level standard and Beijing Transportation Development Research Center according to its "urban road traffic operation evaluation index system" ${ }^{[12]}$ in the form of single-vehicle delay time division, to get the stopping delay time of vehicles at intersections in different average speed zones, as shown in Table 4.

Table 4: Classification of congestion level and waiting time for each road type

\begin{tabular}{|c|c|c|c|c|c|c|}
\hline \multirow{2}{*}{$\begin{array}{l}\text { Roads } \\
\text { Grade }\end{array}$} & & \multicolumn{5}{|c|}{ Intersection waiting time division form } \\
\hline & & Unobstructed & $\begin{array}{c}\text { Basically } \\
\text { unobstructed }\end{array}$ & $\begin{array}{c}\text { Mild } \\
\text { congestion }\end{array}$ & $\begin{array}{l}\text { Moderate } \\
\text { congestion }\end{array}$ & $\begin{array}{c}\text { Severe } \\
\text { congestion }\end{array}$ \\
\hline \multirow[t]{2}{*}{ Expressway } & $\begin{array}{c}\text { Speed } \\
\text { interval } \\
(\mathrm{km} / \mathrm{h})\end{array}$ & $>65$ & $(50,65]$ & $(35,50]$ & $(20,35]$ & $\leq 20$ \\
\hline & $\begin{array}{l}\text { Delay time } \\
\text { (s) }\end{array}$ & 2.5 & 10 & 20 & 40 & 60 \\
\hline \multirow[t]{2}{*}{ Main roads } & $\begin{array}{c}\text { Speed } \\
\text { interval } \\
(\mathrm{km} / \mathrm{h})\end{array}$ & $>40$ & $(30,40]$ & $(20,30]$ & $(15,20]$ & $\leq 15$ \\
\hline & $\begin{array}{l}\text { Delay time } \\
\text { (s) }\end{array}$ & 2.5 & 10 & 20 & 40 & 60 \\
\hline \multirow{2}{*}{$\begin{array}{c}\text { Secondary } \\
\text { roads } \\
\text { Branch } \\
\text { Road }\end{array}$} & $\begin{array}{c}\text { Speed } \\
\text { interval } \\
(\mathrm{km} / \mathrm{h})\end{array}$ & $>35$ & $(25,35]$ & $(15,25]$ & $(10,15]$ & $\leq 10$ \\
\hline & $\begin{array}{l}\text { Delay time } \\
\text { (s) }\end{array}$ & 2.5 & 10 & 20 & 40 & 60 \\
\hline
\end{tabular}

The intersection waiting time is combined with the passenger vehicle idling fuel consumption rate and emission rate to calculate the vehicle idling fuel consumption and idling emissions due to signal control, as shown in Equation 3.

$$
E_{j, i}=T \times P E R_{0}
$$

where $E j, i$ denotes the idle fuel consumption or emission rate of a gas in $\mathrm{g}$; $\mathrm{T}$ denotes the intersection signal delay time in $\mathrm{s}$; and $P E R_{0}$ denotes the idle fuel consumption rate or emission rate of a gas in $\mathrm{g} / \mathrm{s}$.

3.3 Model Validation; In order to ensure the generality of the emission model, the accuracy of the model needs to be verified. The emission model constructed in this paper was used to calculate the roadway emissions of $\mathrm{CO}, \mathrm{HC}$, and $\mathrm{NOx}$, and the calculated amounts were compared with the measured values from the on-board experiments, and the comparison results are shown in Figure 3. 


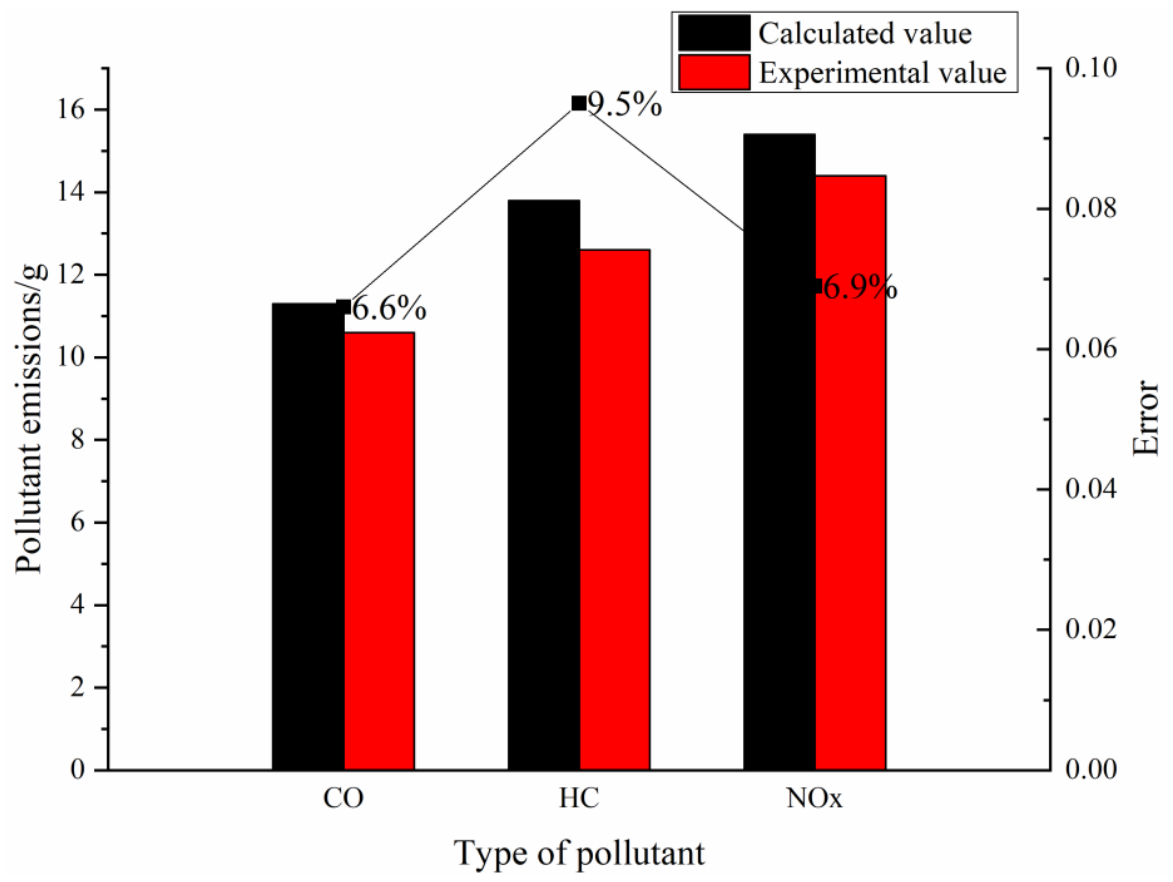

Figure 3: Model validation results

From Figure 3, it can be seen that the errors between the calculated and measured values of the three pollutants are less than $10 \%$, and the model results can be used for the calculation of motor vehicle pollutant emissions on urban roads in Zibo, and the accuracy of the model is good.

\section{CONCLUSION}

In order to comprehensively and accurately respond to the actual road emissions of motor vehicles, this paper establishes a motor vehicle road emission measurement model applicable to the coupling with dynamic traffic network by building an in-vehicle experiment platform based on MAHA METDH6.3 and collecting the emission test data of vehicles in the actual road driving process in real time. The results show that the error between the calculated and measured pollutant values is less than $10 \%$, and the accuracy of the model is good. The results of the study can also be combined with the traffic management of Zibo city to provide a basis for the emission control of motor vehicle pollutants.

\section{REFERENCE.}

1. Ministry of Ecology and Environment of the People's Republic of China. Annual report on environmental management of mobile sources in China [R]. State Council, 2020.

2. Selected editors of this book. Transportation "Twelfth Five-Year" Development Plan [M]. Communist Party History Press, 2011.

3. Yu Ying. Assessment of motor vehicle emissions on arterial roads based on real-time traffic simulation [D]. Southeast University, 2018. 
4. Hao Yanzhao, Wang Hong, Song Guohua, Qiu Zhaowen. Applicability of mesoscopic motor vehicle exhaust model in China [J]. Journal of Chang'an University (Natural Science Edition), 2016, 36(01):112-119.

5. D.Lejri, A. Can, N. Schiper, et al. accounting for traffic speed dynamics when calculating COPERT and PHEM pollutant emissions at the urban scale [J]. Transportation research part D: Transport and Environment, 2018, 63: 588-603.

6. H. Shahbazi, M. Reyhanian, V. Hosseini, et al. The relative contributions of mobile sources to air pollutant emissions in Tehran, Iran: an emission inventory approach [J]. Emission control science and technology, 2016, 2(1): 44-56.

7. H. Perugu, Emission modelling of light-duty vehicles in India using the revamped VSP-based MOVES model: the case study of Hyderabad [J]. Transportation Research Part D: Transport and Environment, 2019, 68: 150-163.

8. Motor Vehicle Emission Monitoring Center, Ministry of Environmental Protection, China. China Motor Vehicle Emission Inventory Model, https://max.book118. com/html/2018/ 1204/8071001135001135.shtm [EB/OL]. 2013-5-24/2020-02-26.

9. X. Q. Xu, Z. Y. Ren, Z. W. Qiu; Impact of Operating Characteristics on Vehicles Emission in the Signal Intersection. Modern Transportation Technology. 2018, 15(03), 62-65.

10. X. F. Sha. Research on Vehicle Dynamic Emission Model on Urban Road.

11. H. B. Liu; Y. G. Xiong; R. Gao; J. Teng; M. Zhu. Investigating Vehicular Energy Consumption and Emissions at Intersections with Micro-Simulation Models. Urban Transport of China.2010,8(02),75-79+24.

12. Beijing Municipal Bureau of Quality and Technical Supervision. Urban road traffic operation evaluation index system [R]. 2011.

\section{*Corresponding Author: Dong GUO;}

Shandong University of Technology, 266 Xincun West Road, Zhangdian District,

Zibo City, Shandong Province ; 15069358986; jiaoyun547@163.com

Online date of publication: 10.09.2021 